\title{
Tropical influence on the summer Mediterranean climate
}

\author{
T. Losada, ${ }^{1}{ }^{\dagger \dagger}$ B. Rodríguez-Fonsecal,2 and F. Kucharski ${ }^{3}$ \\ 'Departamento de Física de la Tierra I, UCM, 28040 Madrid, Spain) \\ 2 Instituto de Geociencias (CSIC-UCM), Facultad de CC. Físicas, 28040 Madrid, Spain \\ ${ }^{3}$ Abdus Salam International Centre for Theoretical Physics, Earth System Physics Section, 34 I 1 Trieste, Italy
}

* Correspondence to:

T. Losada, Departamento de

Física de la Tierra I, UCM, Av.

Complutense s/n, 28040

Madrid, Spain.

E-mail: tldoval@fis.ucm.es

†Current address: Department of Atmospheric and Ocenic

Sciences, University of California,

Los Angeles, CA 90024, USA

Received: 13 September 2010

Revised: 2 September 2011

Accepted: 7 September 2011

\begin{abstract}
Observational evidence shows that, during 1979-2001, the summer Atlantic Niño is related to an increase in the precipitation over the Central Mediterranean and a decrease in the west and east of the basin, a relation absent in previous decades. Using a set of integrations with a global climate model, this work investigates the dynamics underlying such change before and after the 1970s.

We find that the post-1970's response depends on the interactions between the influences from different tropical regions, and that one needs to consider the different impacts of the tropical oceans for the correct prediction of summer Mediterranean climate. Copyright $(c)$ 2011 Royal Meteorological Society
\end{abstract}

Keywords: summer Mediterranean climate; tropical variability; extratropical teleconnections

\section{Introduction}

Mediterranean climate variability is a topic of great interest to climate researchers. It is a region of high vulnerability, influenced by tropical and mid-latitude dynamics (Lionello et al., 2006), which increases the difficulty in the understanding of its climate variability.

A few works have related positive summer sea surface temperature (SST) anomalies in the tropical Atlantic (TA) with colder and wetter conditions in the Western and Central Mediterranean in late summer. The mechanisms include the perturbation of the Hadley cell (Cassou et al., 2005), and the excitation of a Rossby wave train from the Caribbean to Scandinavia (Cassou et al., 2004). Regarding the tropical Pacific, the El Niño Southern Oscillation (ENSO) link with Mediterranean climate seems to have increased at the end of the 20th century (Mariotti et al., 2002), it is stronger for spring and winter, although some significant links are found in other seasons (Brönnimann, 2007, references therein).

All these studies focus on the independent impact of one isolated basin on Mediterranean climate. Nevertheless, observational evidence shows that since the 1970s equatorial SST anomalies in the Atlantic and Pacific appear anti-correlated (Polo et al., 2008; Rodriguez-Fonseca et al., 2009). Moreover, a warming (cooling) in the summer TA has been found to be able to perturb the equatorial Pacific atmosphere favouring the development of a Pacific La Niña (El Niño) (Rodríguez-Fonseca et al., 2009; Losada et al., 2010). Also, an interaction between the Atlantic and Indian tropical basins has been reported for this period (Kucharski et al., 2007, 2008).
Whether these connections between the TA and the rest of the tropical basins can influence the TAMediterranean summer connection is a topic that has not been addressed yet. This possibility is reinforced by the detection of changes in different trends in the Mediterranean from the late 1970s, like those in air temperature (Xoplaki et al., 2006), and in the number of heat waves and droughts (Baldi et al., 2006). Also, the Atlantic-Pacific connection has been identified for the first decades of the 20th century (Joly and Voldoire, 2010), coinciding with a warming trend of the Mediterranean, similar to that described for the 20th century (Giorgi, 2002; Xoplaki, 2006). The latter results suggest a multidecadal modulation of the tropical-extratropical teleconnections, that could be very important for the improvement of seasonal forecasting systems.

Finally, the extratropical SSTs have a weak but not negligible influence on the atmosphere (Kushnir et al., 2002). Cassou et al. (2004) have found that the summer TA atmosphere can force, at least in part, the extratropical North Atlantic SSTs in late summer. Such ocean-atmosphere feedback could be important in the modulation of the final atmospheric response to tropical SSTs.

This article shows that the interannual TA-summer Mediterranean relationship is not stationary and, depending on the time period, the rest of the tropical basins may play a determinant role in the modulation of the signal. The dynamical mechanisms underlying the different response in the post-1970s are analysed.

First, we determine the observed Mediterranean response to the TA SST anomalies before and after the 1970s. In the second step, we analyse the influence of 
the interactions between the tropical basins in the post1970's response taking into account the extratropical ocean-atmosphere feedbacks, by performing sets of simulations with an Atmospheric General Circulation Model (AGCM) coupled to a Slab Ocean Model (SOM) in the Euro-Atlantic sector.

The methodology applied in the study is described in Section 2, Section 3 shows the main results, and the discussion and conclusions are given in Section 4.

\section{Data and methodology}

The observed monthly data used in this work are CPC Merged Analysis of Precipitation (CMAP) (Xie and Arkin, 1997) and Climate Research Unit (CRU) (Hulme et al., 1992) precipitation datasets, HadISST1 SST dataset (Rayner et al., 2003), and ERA40 $200 \mathrm{hPa}$ geopotential height (Uppala et al., 2005).

We have applied Extended Maximum Covariance Analysis (EMCA, Polo et al., 2008) to the non-detrended standardized June-July-August (JAS) monthly anomalous rainfall $\left(30^{\circ} \mathrm{N}-50^{\circ} \mathrm{N}, 15^{\circ} \mathrm{W}-\right.$ $40^{\circ} \mathrm{E}$ ) and to the detrended March-April-May (MAM) to October-November-December (OND) monthly anomalous SST $\left(30^{\circ} \mathrm{S}-10^{\circ} \mathrm{N}, 60^{\circ} \mathrm{W}-35^{\circ} \mathrm{E}\right)$, in order to discriminate in the same mode a sequence of SST anomalies explaining the highest co-variability with the JAS Mediterranean precipitation.

EMCA analysis has been applied to the observed data for two sub-periods: 1958-1978 and 1979-2001. We have chosen 1978/1979 as the cutting date because the satellite-based rainfall dataset CMAP is available from 1979, ensuring the spatial continuity of the rainfall patterns and the homogeneity of the data. Also, this cutting allows us to compare the results with other recent works (Rodriguez-Fonseca et al., 2009; Mohino et al., 2010).

The global EMCA expansion coefficient (EC) of the predictant field (SST) computed for each sub-period will be used as an index expressing the maximum covariance between SST and rainfall (SST-EC index).

To discriminate the impact of different tropical basins in the response, this index is used to regress the outputs of several ten-member ensemble simulations performed with the International Centre for Theoretical Physics (ICTP) AGCM (Speedy model), version 40 , with a horizontal resolution of T30 and eight vertical levels (Kucharski et al., 2007). The simulations cover the period 1949-2002 and have been designed by adding the observed monthly SST anomalies either in the TA, Pacific or Indian basin (TropAtl, TropPac and TropInd simulations) to the SST climatology. A 34-member ensemble control simulation with observed 1949-2002 monthly mean SST prescribed everywhere (Global simulation) has been performed in order to test the reliability of the model in reproducing the observed responses.

To address the importance of the extratropical ocean-atmosphere interactions, all the simulations have been re-done, coupling the AGCM to a SOM (Kucharski et al., 2006) in the North Atlantic (north of $30^{\circ} \mathrm{N}$ ) and Mediterranean Sea (TropAtl_SOM, TropPac_SOM and TropInd_SOM simulations).

Finally, two more 34-member experiments have been defined, covering the same 1949-2002 period, and adding observed monthly SST anomalies in the whole tropical oceans to the climatology, with the model uncoupled (GlobTrop simulation), and coupled in the North Atlantic and Mediterranean (GlobTrop_SOM simulation).

The statistical significance of the results is determined with a $t$-test of correlation. Areas in which the responses are significant with a $95 \%$ of confidence level are highlighted throughout the study.

\section{Results}

Results of the first EMCA mode for 1958-1978 and 1979-2001 periods are depicted in Figure 1. The analysis is performed with CRU data for the first period and with CMAP and CRU data for the second.

The two EMCAs for the second period show high spatial coherence in both rainfall and SST patterns. Correlation between the two ECs is 0.99 (0.77) for SST (precipitation), pointing to the robustness of the results.

For both periods, the SST map shows a pattern that strongly resembles the Atlantic Niño (Zebiak, 1993). The spatial structures of the SST anomalies show some differences between periods, similar to those observed when regressing the SSTs onto the Atl3 index [calculated as the anomalous SST averaged between $\left(3^{\circ} \mathrm{S}-3^{\circ} \mathrm{N}, 20^{\circ} \mathrm{W}-0^{\circ} \mathrm{E}\right)$; Figure $1 \mathrm{c}$ in RodríguezFonseca et al., 2009]. The correlation coefficients between the ECs and the Atl3 are 0.59 and 0.77 for the first and second period of study respectively; thus, the variability of the JAS Mediterranean precipitation is highly linked to the tropical Atlantic variability (TAV), especially during the second period.

Precipitation maps show differences between periods in the northeast of Spain, south of France and in the Eastern Mediterranean. Over these regions, the precipitation anomalies associated with the TAV change from positive to negative in relation to a TA anomalous warming. The differences between the correlation maps of both periods are significant at a $95 \%$ confidence level in the regions mentioned above (not shown).

Those differences in the precipitation response could be due to the change in the structure of the TA SST anomalies between the two periods: in the first period, the equatorial anomalies only reach $30^{\circ} \mathrm{W}$ longitude; in the second one they have a more zonal structure, covering the whole tropical basin. A warmer Caribbean would lead to an enhancement of the convection that could trigger a Rossby wave into the European region (Cassou et al., 2004; GarcíaSerrano et al., 2008). However, the regression of the 
(a)

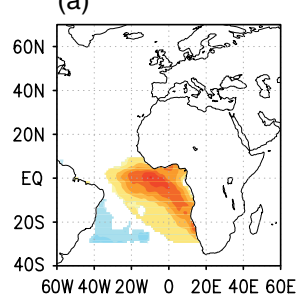

(b)

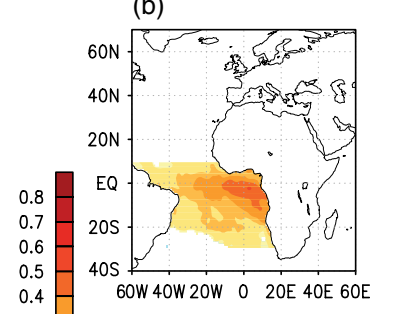

(c)

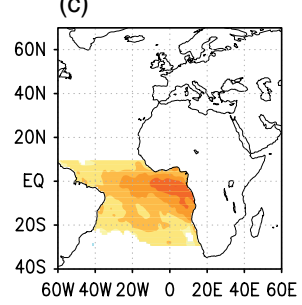

CRU 58-78 ruv $=0.65$ scf $=0.25$

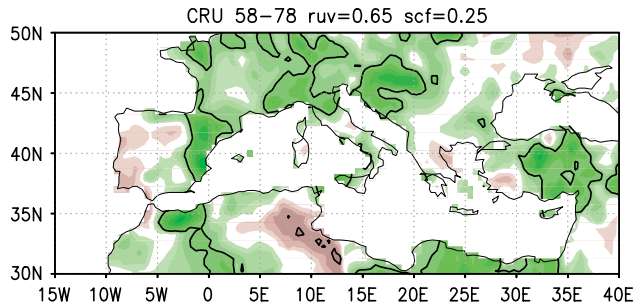

CRU 79-01 ruv=0.57 scf $=0.26$

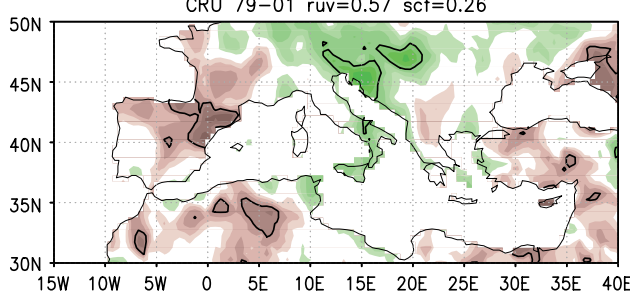

CMAP 79-01 ruv $=0.61 \quad \mathrm{scf}=0.30$

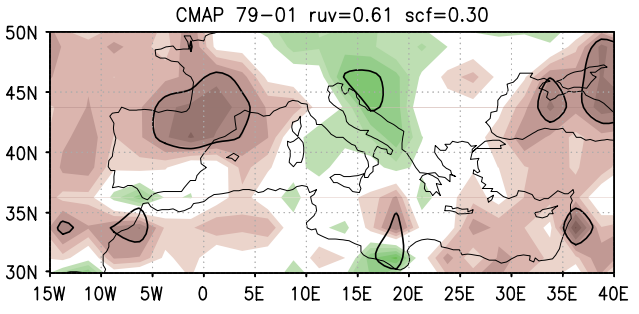

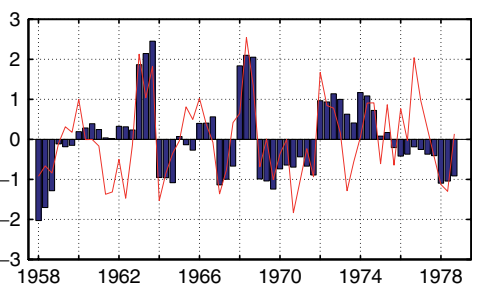
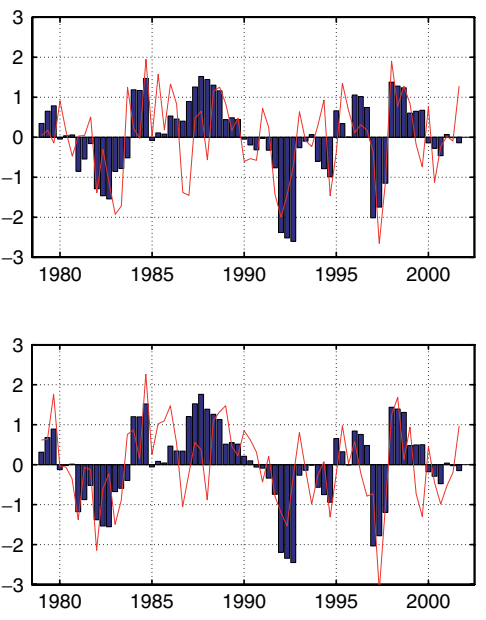

$\begin{array}{lllllllll}-0.4-0.35-0.3-0.25-0.2-0.15-0.1-0.050 .05 & 0.1 & 0.15 & 0.2 & 0.25 & 0.3 & 0.35 & 0.4\end{array}$

Figure I. First EMCA mode between JAS-observed Mediterranean precipitation anomalies and MAM to OND tropical Atlantic SSTs anomalies. (Left) Homogeneous SST maps for JAS season $\left({ }^{\circ} \mathrm{C}\right.$ ). (Center) Heterogeneous maps for JAS precipitation (standarized anomalies). (Right) EC for global SST (bars) and precipitation (red line). (a) 1958-I978 EMCA. (b) I979-200I EMCA performed with CRU data. (c) 1979-200I EMCA performed with CMAP data.

global SSTs onto the SST-EC (Figure 2(a)) shows anti-correlated SST anomalies in the TA and Pacific (Rodriguez-Fonseca et al., 2009), as well as positive SST anomalies over the maritime continent and a positive lobe of anomalous SST in the North Atlantic, similar to the one that Cassou et al. (2004) reported to be forced by the atmosphere. These SST anomalies outside the TA region could also be responsible for the observed changes.

The regression of the ERA40 $200 \mathrm{hPa}$ geopotential height onto the SST-EC (Figure 2(b)) shows a global extratropical atmospheric response with a circumglobal wave pattern (Ding and Wang, 2005) that presents a negative lobe over Europe and the Central Mediterranean, which could be producing the increase in the precipitation over these areas. This lobe appears surrounded by positive geopotential height anomalies, which could lead to the negative anomalous precipitation observed in the Eastern and Western Mediterranean. During the pre-1970s, a warming in the TA appears together with a slight warming in the Central Pacific and the Western India, and it is related to an upper level ridge over North-Eastern Europe (not shown).

We analyse the results of the simulations by regressing the simulated precipitation onto the SSTEC. Global simulation results (Figure 3(a)) reproduce the change in precipitation observed over the western and eastern part of the Mediterranean Basin, but it fails in the representation of the Central Mediterranean precipitation anomalies, because of a more zonal disposition of the anomalies in the simulation.

None of the isolated tropical basins are able to reproduce the observed response in the Mediterranean precipitation, either by themselves or coupled to a SOM in the North Atlantic (not shown). The only simulation that fairly captures the observed precipitation pattern is GlobTrop_SOM (Figure 3(b)). The need of the SOM is confirmed by comparing the latter with GlobTrop results (Figure 3(c)), which depict the wrong precipitation response in the Central Mediterranean. In GlobTrop_SOM results, the differences in the correlation maps between periods resemble the observations in the Western and Eastern Mediterranean with a $95 \%$ significant level of confidence (not shown).

The upper level atmospheric responses for each of the 'one-basin' experiments show a wave-like pattern emerging from the tropical heat source and trapped into the mid-latitude jet, but none of them presents the correct modulation of the wave over the region of study (not shown). Figure 4 shows z200 disturbances for Global, TropGlob and TropGlob_SOM, together with $200-\mathrm{hPa}$ mean winds. The three anomalous patterns, especially the TropGlob_SOM one, are similar to the observed ones over Europe and the Mediterranean, although the amplitude of the anomalies over Europe 
(a) Regr SST 79-01 HadISST

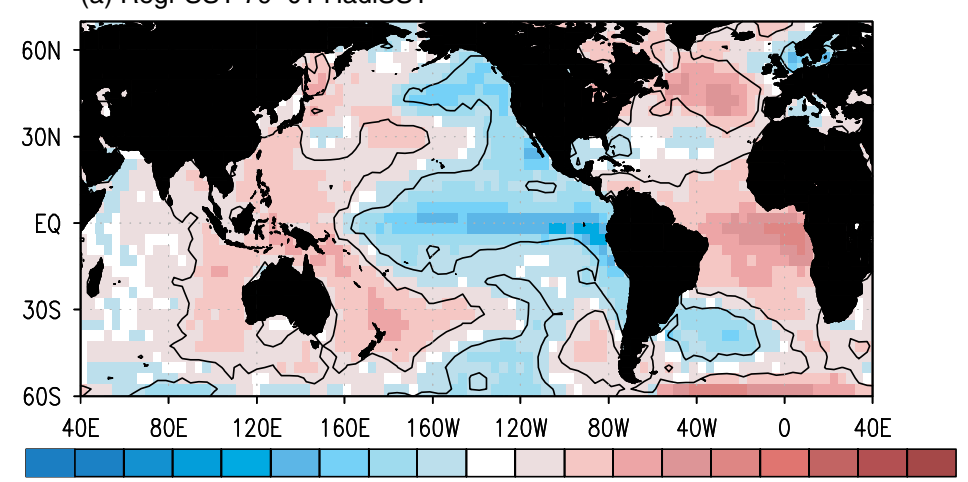

$-0.8-0.7-0.6-0.5-0.4-0.3-0.2-0.1-0.010 .010 .1 \quad 0.2 \quad 0.3 \quad 0.4 \quad 0.5 \quad 0.6 \quad 0.7 \quad 0.8$

(b) Mean $200 \mathrm{hPa}$ wind - Regr z200 79-01 ERA40

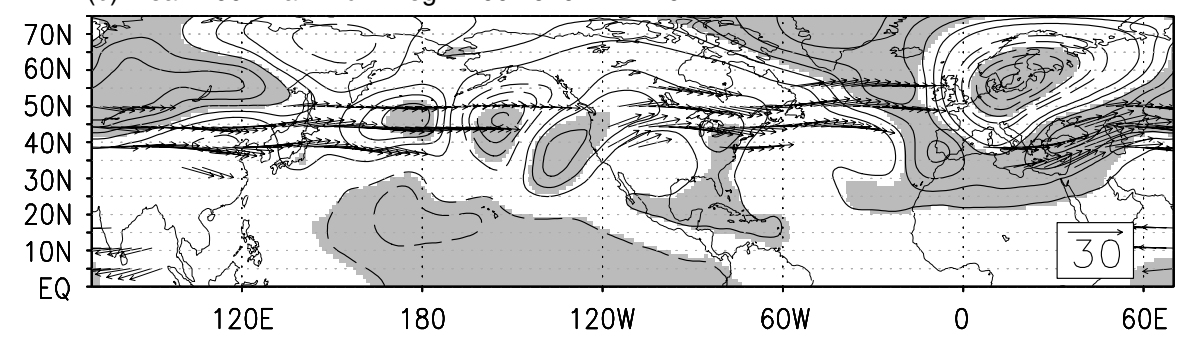

Figure 2. (a) Regression of 1979-200I global anomalous JAS SSTs $\left({ }^{\circ} \mathrm{C}\right)$ onto the SST-EC. Contours denote significant areas at $95 \%$ confidence level. (b) 1979-200I mean JAS $200 \mathrm{hPa}$ zonal wind (arrows) and regression of the $200 \mathrm{hPa}$ JAS geopotential height $(\mathrm{m})$ anomalies onto the SST-EC for ERA40 data. Contour interval is $3 \mathrm{~m}$. Grey shading denotes significant areas at $95 \%$ confidence level.

(a) Regr prcp 79-01 Global SST

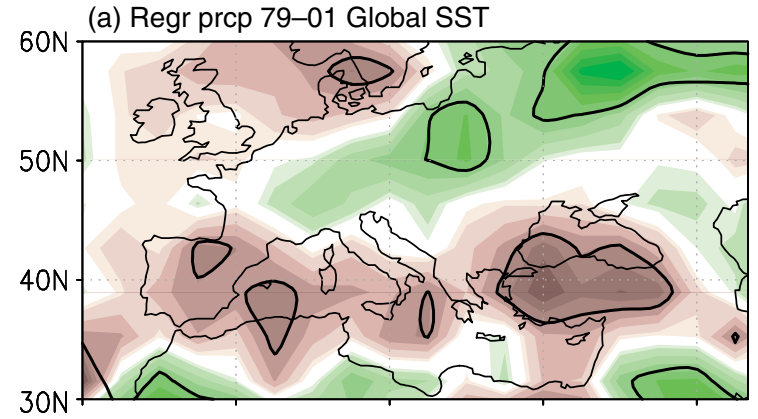

(c) Regr prcp 79-01 GlobTrop

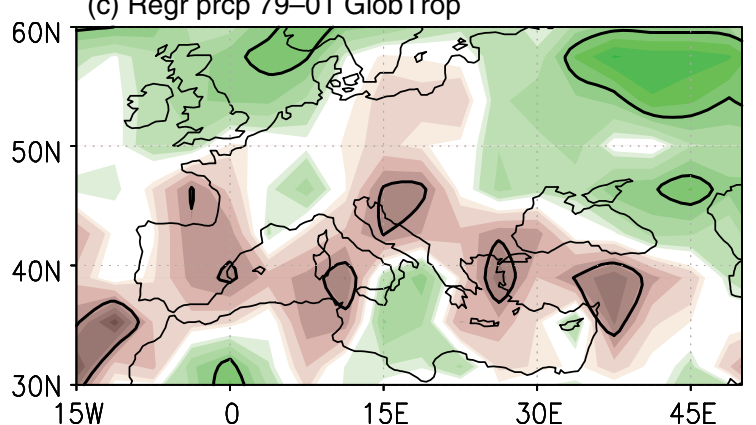

(b) Regr prcp 79-01 GlobTrop_SOM

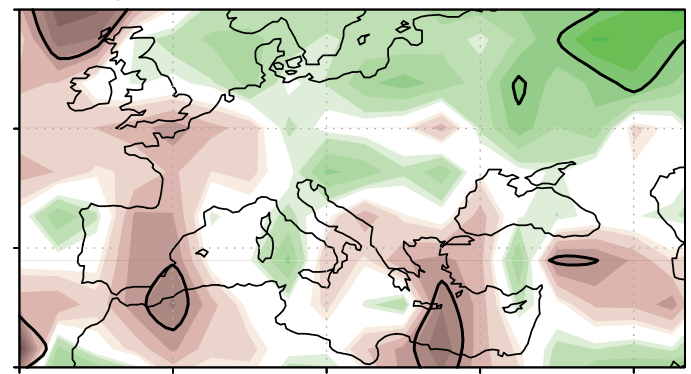

(d) Regr prcp 79-01 CMAP

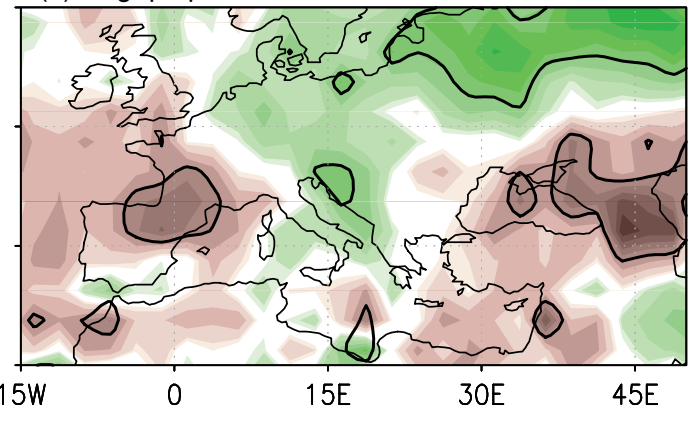

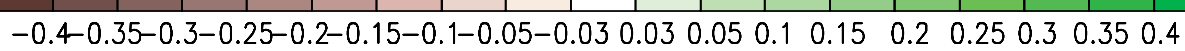

Figure 3. Regression of standarized anomalies of precipitation during JAS onto the SST-EC for (a) Global, (b) GlobTrop_SOM, (c) GlobTrop simulations, and (d) CMAP data. Black contours mark $95 \%$ significant areas.

is weaker than the observed ( -18 for observations, -5 for GlobTrop_SOM). They show a wave-like pattern arising from the tropical Pacific that travels to the Atlantic sector trapped in the jetstream. They also show a positive lobe over the Caribbean Sea that could be the source of another wave towards Europe. Although the negative lobes of the extratropical wave tend to disappear in the simulations, they present relative minima quite well located (around $180^{\circ} \mathrm{W}$ and $100^{\circ} \mathrm{W}$ ). GlobTrop_SOM shows a relative 


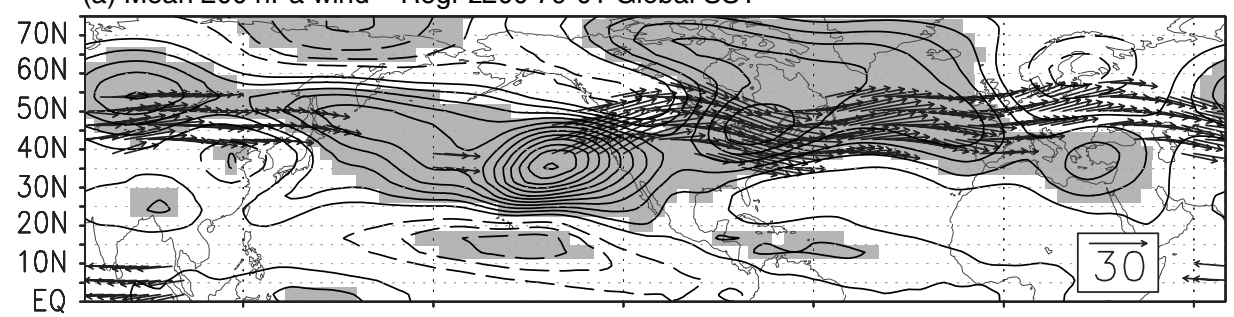

(b) Mean 200 hPa wind - Regr z200 79-01 GlobTrop

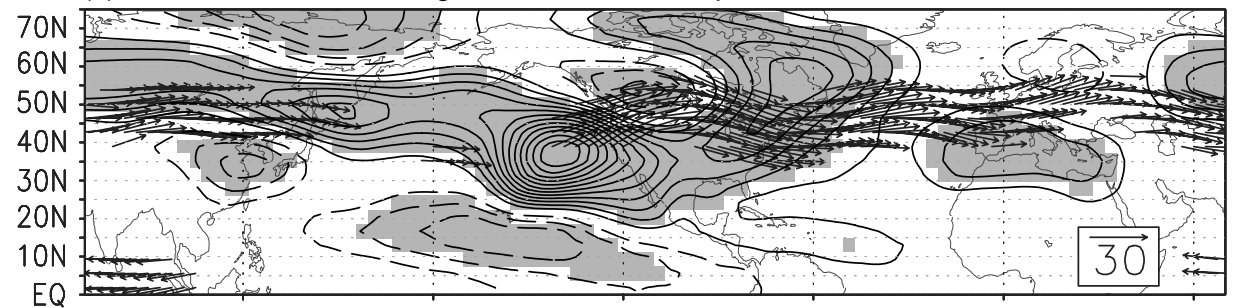

(c) Mean $200 \mathrm{hPa}$ wind - Regr z200 79-01 GlobTrop_SO

$\mathrm{M}$

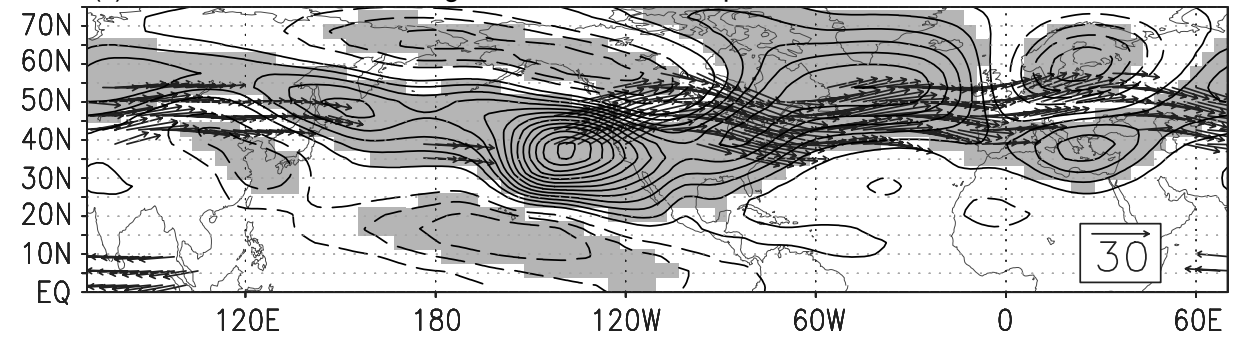

Figure 4. Mean $200 \mathrm{hPa}$ wind (arrows) and regression of JAS z200 anomalies (m) onto the SST-EC for (a) Global, (b) GlobTrop, (c) GlobTrop_SOM (contours). Contour interval is I m; shading denotes $95 \%$ significant areas.

minimum over the western North Atlantic, similar to the observed one, although shifted to the south and with a more zonal configuration. This lobe, in turn, influences the location of the next positive lobe, leading to a more correct modulation of the wave over Europe and the Mediterranean.

The major difference between the simulated and observed z200 anomalies is found over the Central North Pacific. As shown by Ding and Wang (2005), the observed pattern could be forced by the perturbation of the flow in the North Atlantic region. In the model, the misrepresentation of the jetstream over the North Pacific could be responsible for the wrong representation of this signal coming from the Atlantic sector.

Nevertheless, the model is able to capture the impact of the Pacific anomalies in the North Atlantic, because the upper level anomalies produced in that sector can enter the jetstream at $130^{\circ} \mathrm{W}$ and travel to Europe.

The warm SSTs over the maritime continent influence the response by producing anomalous descent over the Eastern Mediterranean (Rodwell and Hoskins, 2001), enhancing the anomalous lobe of positive z200 anomalies there. In fact, simulations forcing with anomalous SST over the TA and Pacific, but not over the Indian Ocean, fail in the representation of the positive lobe of anomalous z200 over the Eastern Mediterranean (not shown).

The sum of the z200 regressions of TropInd, TropAtl and TropPac simulations produces an extratropical response over the Mediterranean which is different from the response produced by the global tropical forcing (not shown), suggesting an interaction between waves, and not just a linear superposition.

Figure 5 shows the regression of the North Atlantic SST anomalies generated in the GlobTrop_SOM simulation onto the SST-EC. The pattern clearly resembles the observed one over the North Atlantic, although the amplitude of the anomalies is much weaker and the location of the lobes is shifted northward. The rest of the coupled simulations fail in representing the observed SST pattern (not shown). Thus, the local air-sea interactions appear as crucial in the correct

Regr SST 79-01 GlobTrop_SOM

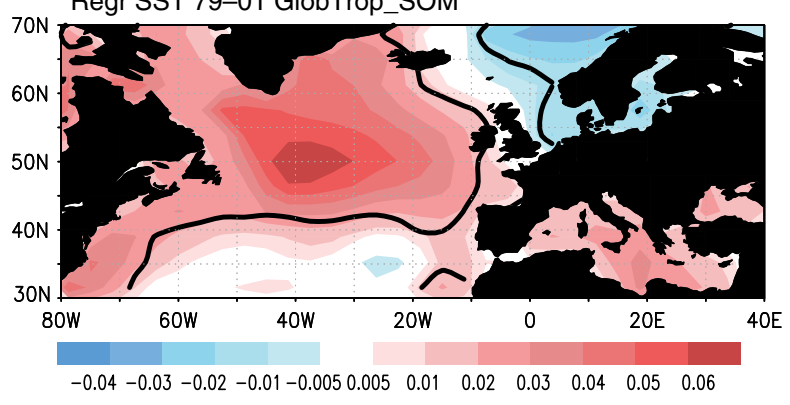

Figure 5. Regression of the 1979-200I simulated SST anomalies $\left({ }^{\circ} \mathrm{C}\right)$ for GlobTrop_SOM simulation. Contours denote $95 \%$ significant areas. 
simulation of the atmospheric response in the region of study.

Our results strongly suggest that, in order to reproduce the observed precipitation pattern associated with the TAV in late summer, the interaction between the different tropical ocean basins is necessary, and that the local ocean-atmosphere feedbacks are a key factor in the right modulation of the response.

\section{Summary and conclusions}

Observational analysis shows that the co-variability between TA SST and JAS Mediterranean precipitation has changed from the 1970s, especially in the western and eastern parts of the Mediterranean Basin. The results suggest that the change is produced by an alteration in the relationship between tropical ocean basins. After the 1970s, the Atlantic Niño appears together with anomalies of the opposite sign in the Central Pacific, and anomalies of the same sign in the maritime continent (Rodriguez-Fonseca et al., 2009), producing the excitation of different Rossby waves from each of the tropical oceans, and an extratropical Rossby wave trapped in the jet. The large-scale atmospheric anomalies in the North Atlantic, at the exit of the jet, have the form of an anomalous cyclonic circulation surrounded by anomalous highs, and could be responsible for the anomalous precipitation pattern. The concomitant extratropical SST anomalies over the North Atlantic Ocean may also play a role in the final modulation of the response.

Different simulations performed with the ICTP AGCM show that none of the isolated tropical basins are able to reproduce the observed response in the Mediterranean precipitation, either by themselves or coupled to a SOM in the North Atlantic. The only simulation capable of producing a precipitation pattern similar to the observed during 1979-2001 is the one forced with observed SST over the whole tropics and coupled to a SOM in the North Atlantic and Mediterranean.

This result supports the hypothesis about the joint effect of the global tropical basins in the response, and about the key role played by local thermodynamical ocean-atmosphere feedbacks in the correct modulation of the wave over the North Atlantic sector, highlighting that extratropical responses to tropical anomalies are likely to be complex, depending on interactions of influences from various regions, and the need for considering the different behaviour of the tropical oceans before and after the 1970s, in order to get a correct prediction of the summer Mediterranean climate.

Predictability over the Mediterranean and European region is low, and there is no clear skill for seasonal forecast of precipitation over Europe (Frías et al., 2010, references therein). Results of this work suggest that, in order to accurately predict the atmospheric response to the ocean-forcing patterns, those systems need to improve the simulation of the variability of phenomena different than ENSO, such as the TA, and of the interaction between ocean basins.

\section{Acknowledgements}

This work has been supported through Spanish projects CGL2006-04471, MOVAC-200800050084028 and CGL200910285 , as well as by the EG/2170 exchange grant provided by the ESF MedCLIVAR Programme.

\section{References}

Baldi M, Dalu G, Maracchi G, Pasqui M, Cesarone F. 2006. Heat waves in the Mediterranean: a local feature or a larger-scale effect? International Journal of Climatology 26: 1477-1487.

Brönnimann S. 2007. Impact of El Niño-Southern Oscillation on European climate. Reviews of Geophysics 45: RG3003. DOI:10.1029/2006RG000199.

Cassou C, Desert C, Terray L, Hurrell JW, Drévillon M. 2004. Summer sea surface temperature conditions in the North Atlantic and their impact upon the atmospheric circulation in early winter. Journal of Climate 17: 3349-3363.

Cassou C, Terray L, Phillips AS. 2005. Tropical Atlantic influence on European heat waves. Journal of Climate 18: 2805-2811.

Ding Q-H, Wang B. 2005. Circumglobal teleconnection in the Northern hemisphere summer. Journal of Climate 18: 3483-3505.

Frías MD, Herrera S, Cofiño AS, Gutiérrez JM. 2010. Assessing the skill of precipitation and temperature seasonal forecasts in Spain: windows of opportunity related to ENSO events. Journal of Climate 23: 209-220. DOI: 10.1175/2009JCLI2824.1.

García-Serrano J, Losada T, Rodríguez-Fonseca B, Polo I. 2008. Tropical Atlantic variability modes (1979-2001). Part II: timeevolving atmospheric circulation related to SST-forced. Journal of Climate 21: 6476-6497.

Giorgi F. 2002. Variability and trends of sub-continental scale surface climate in the twentieth century. Part I: observations. Climate Dynamics 18: 675-691.

Hulme M. 1992. A 1951-80 global land precipitation climatology for the evaluation of general circulation models. Climate Dynamics 7: 57-72.

Joly M, Voldoire A. 2010. Role of the Gulf of Guinea in the interannual variability of the West African monsoon: what do we learn from CMIP3 coupled simulations?. International Journal of Climatology 30: 1843-1856. DOI: 10.1002/joc.2026.

Kucharski F, Molteni F, Bracco A. 2006. Decadal interactions between the western tropical Pacific and the North Atlantic Oscillation. Climate Dynamics 26: 79-91.

Kucharski F, Bracco A, Yoo JH, Molteni F. 2007. Low-frequency variability of the Indian monsoon-ENSO relationship and the Tropical Atlantic: The "weakening" of the 1980s and 1990s. Journal of Climatology 20: 4255-4266.

Kucharski F, Bracco A, Yoo JH, Molteni F. 2008. Atlantic forced component of the Indian monsoon interannual variability. Geophysical Research Letters 35: L04706. DOI: 10.1029/2007GL033037.

Kushnir Y, Robinson WA, Bladé I, Hall NMJ, Peng S, Sutton R. 2002. Atmospheric GCM response to extratropical SST anomalies: synthesis and evaluation. Journal of Climatology 15: 2233-2256.

Lionello P, Malanotte-Rizzoli P, Boscolo R, Alpert P, Artale V, Li L, Luterbacher J, May W, Trigo R, Tsimplis M, Ulbrich U, Xoplaki E. 2006. The Mediterranean climate: An overview of the main characteristics and issues. Developments in Earth and Environmental Sciences, 4: 1-26. DOI: 10.1016/S1571-9197(06)80003-0.

Losada T, Rodriguez-Fonseca B, Polo I, Janicot S, Gervois S, Chauvin F, Ruti P. 2010. Tropical response to the Atlantic Equatorial mode: AGCM multimodel approach. Climate Dynamics 35: 45-52. DOI: 10.1007/s00382-009-0624-6.

Mariotti A, Zeng N, Lau K-M. 2002. Euro-Mediterranean rainfall and ENSO-A seasonally varying relationship. Geophysical Research Letters 29(12): 1621. DOI: 10.1029/2001GL014248. 
Mohino E, Rodríguez-Fonseca B, Losada T, Gervois S, Janicot S, Bader J, Ruti P, Chauvin F. 2010. Changes in the interannual SSTforced signals on West African rainfall. AGCM intercomparison. Clim. Dyn. DOI: 10.1007/s00382-011-1093-2.

Polo I, Rodríguez-Fonseca B, Losada T, García-Serrano J. 2008. Tropical Atlantic variability modes (1979-2002). Part I: time-evolving SST modes related to West African rainfall. Journal of Climate 21: 6457-6475. DOI: 10.1175/2008JCLI2607. 1.

Rayner NA, Parker DE, Horton EB, Folland CK, Alexander LV, Rowell DP, Kent EC, Kaplan A. 2003. Global analyses of sea surface temperature, sea ice, and night marine air temperature since the late nineteenth century. Journal of Geophysical Research. 108(D14): 4407. DOI: 10.1029/2002JD002670.

Rodríguez-Fonseca B, Polo I, García Serrano J, Losada T, Mohino E, Mechoso CR, Kucharski F. 2009. Are Atlantic Niños enhancing Pacific ENSO events in recent decades?. Geophysical Research Letters 36: L20705. DOI: 10.1029/2009GL040048.

Rodwell MJ, Hoskins BJ. 2001. Subtropical anticyclones and summer monsoons. Journal of Climate 14: 3192-3211.
Uppala SM, Kållberg PW, Simmons AJ, Andrae U, Bechtold VDC, Fiorino M, Gibson JK, Haseler J, Hernandez A, Kelly GA, Li X, Onogi K, Saarinen S, Sokka N, Allan RP, Andersson E, Arpe K, Balmaseda MA, Beljaars ACM, Berg LVD, Bidlot J, Bormann N, Caires S, Chevallier F, Dethof A, Dragosavac M, Fisher M, Fuentes M, Hagemann S, Hólm E, Hoskins BJ, Isaksen L, Janssen PAEM, Jenne R, Mcnally AP, Mahfouf J-F, Morcrette J-J, Rayner NA, Saunders RW, Simon P, Sterl A, Trenberth KE, Untch A, Vasiljevic D, Viterbo P, Woollen J. 2005. The ERA-40 reanalysis. Quarterly Journal of the Royal Meteorological Society 131: 2961-3012. DOI: $10.1256 / \mathrm{gj} 04176$.

Xie P, Arkin PA. 1997. Global precipitation: A 17-year monthly analysis based on gauge observations, satellite estimates, and numerical model outputs. Bulletin of the American Meteorological Society 78: 2539-2558.

Xoplaki E, Luterbacher J, González-Rouco JF. 2006. Mediterranean summer temperature and winter precipitation, large-scale dynamics, trends. Il Nuovo Cimento 29: 45-54.

Zebiak SE. 1993. Air-sea interaction in the equatorial Atlantic region. Journal of Climate 6: 1567-1586. 